\title{
Die Europäische Union 2007: ein Rückblick
}

Das Jahr 2007 erbrachte mehrere Ereignisse, die die Europäische Union mittelund langfristig prägen werden. Zunächst wurden zu Jahresbeginn mit Bulgarien und Rumänien zwei neue Mitglieder aufgenommen, hinzu trat der Beitritt Sloweniens zur Gemeinsamen Währung. Vor allem aber gelang den Mitgliedstaaten mit der Verabschiedung des „Vertrags von Lissabon“ eine zumindest formale Lösung der „Verfassungskrise“. Die vorliegende Dokumentation informiert über die wichtigsten Ereignisse und Entwicklungen im Rahmen der Europäischen Union im Verlauf des Jahres 2007. Wie in den bisherigen Beiträgen dieser Reihe ${ }^{1}$ orientiert sich die Darstellung an der Struktur des EUV. Zunächst werden die übergeordneten Entwicklungen nachgezeichnet, die die Union insgesamt betreffen (I.); dem folgen Abschnitte zu den einzelnen „Säulen“: den Politiken des EGV (II.-IV.), der Gemeinsamen Außen- und Sicherheitspolitik (V.) sowie der polizeilichen und justiziellen Zusammenarbeit in Strafsachen (VI.).

\section{I. Übergeordnete Entwicklungen der Europäischen Union}

\section{Reform der vertraglichen Grundlagen}

Den im Jahr 2004 unterzeichneten „Vertrag über eine Verfassung für Europa“ (VVE), der die Union auf eine neue primärrechtliche Grundlage stellen sollte, ${ }^{2}$ hatten zu Beginn des Berichtsjahres 18 der 27 Mitgliedstaaten ratifiziert, ${ }^{3}$ in zwei weiteren (Frankreich und den Niederlanden) war das Verfahren jedoch gescheitert; vor diesem Hintergrund ließen die übrigen Staaten ihre Verfahren ruhen.

1 Zuletzt Schubert, S.: Die Europäische Union 2006: ein Rückblick, in: ZSE, 5/1 (2007), 112-146.

2 Vgl. ausführlich Hesse, J.J.: Vom Werden Europas. Der Europäische Verfassungsvertrag: Konventsarbeit, politische Konsensbildung, materielles Ergebnis, Berlin, 2007.

3 Dies schließt zwei Staaten (Bulgarien und Rumänien) ein, die kein eigenes Ratifizierungsverfahren durchführten, da die Zustimmung zum VVE Teil des Beitrittsvertrages war, sowie zwei weitere (Deutschland und die Slowakei), in denen zwar jeweils die Zustimmung des Parlaments vorlag, die Hinterlegung der Ratifikationsurkunde durch das Staatsoberhaupt aufgrund anhängiger Verfassungsbeschwerden jedoch zunächst nicht erfolgt war. Vgl. Schubert, S., a.a. O., 112-116 m.w. N. 
Die deutsche Ratspräsidentschaft des ersten Halbjahres 2007 wurde beauftragt, einen Bericht über Stand und Perspektiven der Vertragsreform vorzulegen.

Allgemein wurde davon ausgegangen, dass ein Festhalten am VVE in der vorliegenden Fassung keine realistische Option darstellte, da zum einen weder in Frankreich noch in den Niederlanden absehbar war, wie nach den negativ ausgegangenen Referenden eine Ratifizierung politisch durchzusetzen wäre, und zum anderen auch in anderen Mitgliedstaaten (etwa in Polen und dem Vereinigten Königreich) erhebliche Widerstände gegen den VVE bestanden. Allerdings erklärten jene Staaten, die den VVE ratifiziert hatten, mehrfach ihren Willen, die inhaltliche Substanz des Vertrags zu erhalten. ${ }^{4}$

Für einen ersten Schritt aus der Krise nutzte die deutsche Bundesregierung das 50. Jubiläum der Unterzeichnung der Römischen Verträge. Auf einer aus diesem Anlass einberufenen informellen Tagung des Europäischen Rates wurde am 25. März die sog. ,,Berliner Erklärung “ unterzeichnet. ${ }^{5}$ Neben einer Würdigung der bisherigen Erfolge des Integrationsprozesses und einer Bekräftigung der gemeinsamen Werte und Ziele äußerte sie sich zur Frage der Vertragsreform. Demnach seien die Organe und Mitgliedstaaten der Union ,in dem Ziel geeint, die Europäische Union bis zu den Wahlen zum Europäischen Parlament 2009 auf eine erneuerte gemeinsame Grundlage zu stellen “6. Damit war die Erklärung seit den negativen Referenden von 2005 die erste gemeinsame Äußerung der mitgliedstaatlichen Regierungen, die den grundsätzlichen Willen zu einer Vertragsreform bekräftigte. Der genaue Wortlaut war bis zuletzt umstritten, da vor allem die tschechische Regierung eine Festlegung vermeiden wollte; auch weitere Mitgliedstaaten hatten Bedenken. Daher wurde die Erklärung auch nicht - obwohl gegen die Endfassung keine Regierung mehr Einwände vortrug - von allen Staats- bzw. Regierungschefs unterzeichnet, sondern in deren Anwesenheit lediglich durch die Präsidenten des Europäischen Parlaments (Pöttering), des Europäischen Rates (Merkel) und der Europäischen Kommission (Barroso). ${ }^{7}$

Konkrete Schritte wurden erst nach der französischen Präsidentschaftswahl am 22. April (1. Wahlgang) bzw. 6. Mai (2. Wahlgang) erwartet, da Frankreich nicht

4 FAZ vom 27.01. 2007.

5 Erklärung anlässlich des 50. Jahrestages der Unterzeichnung der Römischen Verträge vom 25.03. 2007, abrufbar unter http://europa.eu/50/docs/berlin_declaration_de.pdf.

6 Ebd., Abschnitt III.

$7 \quad$ FAZ vom 26.03. 2007. 
nur als ,großem“ EU-Mitglied traditionell besondere Bedeutung zukommt, sondern es auch zu den Staaten gehörte, deren Bevölkerung den VVE in einem Referendum abgelehnt hatte. Hinzu kam, dass Amtsinhaber Jacques Chirac sich nicht mehr zur Wahl stellte und die beiden aussichtsreichsten Kandidaten, der Gaullist Nicolas Sarkozy und die Sozialistin Ségolène Royal, im Wahlkampf unterschiedliche Positionen zur europäischen „Verfassungsfrage“ erkennen ließen: Royal trat für die Ausarbeitung eines neuen Textes ein, der die „soziale Dimension" stärker berücksichtigen und erneut dem Volk zur Ratifizierung vorgelegt werden sollte. Sarkozy hingegen warb für einen deutlich verschlankten Text, der die wesentlichen institutionellen Reformen des VVE übernehmen und auf parlamentarischem Wege ratifiziert werden sollte. ${ }^{8}$ Aus dem zweiten Wahlgang ging Sarkozy mit 53,06\% der Stimmen als Sieger hervor. ${ }^{9}$

Die Ratspräsidentschaft bemühte sich gleichfalls darum, einen möglichst großen Teil der im VVE vorgesehenen Reformen zu übernehmen, zugleich aber auf die „Verfassungssymbolik“ zu verzichten, um so eine rein parlamentarische Ratifizierung auch in jenen Staaten politisch rechtfertigen zu können, die über den VVE ein Referendum abgehalten oder angekündigt hatten. Am 14. Juni legte der Vorsitz den erbetenen Bericht zum Stand der Verhandlungen vor. ${ }^{10}$ Darin wurde die unverzügliche Einberufung einer Regierungskonferenz vorgeschlagen, die ihre Beratungen vor Jahresende abschließen sollte. Zudem wurde empfohlen, zur

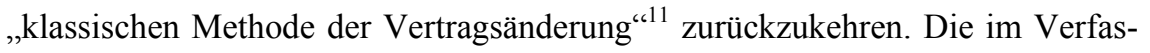
sungsvertrag enthaltenen Reformen würden die materielle Grundlage darstellen, wobei in einigen Bereichen Änderungsbedarf eingeräumt wurde.

Vorgesehen war, bereits auf der Sitzung des Europäischen Rats vom 21./22. Juni die wesentlichen inhaltlichen Fragen zu klären, so dass die Regierungskonferenz den Vertragstext nur noch technisch ausarbeiten müsste. Im Vorfeld brachten vor allem die Regierungen Polens und des Vereinigten Königreichs Forderungen vor, die sie mit der Drohung verbanden, ggf. ihre - für einen Beschluss erforderliche - Zustimmung zu verweigern. Der britischen Regierung ging es vor allem darum, eine Rechtsverbindlichkeit der Grundrechtecharta zu verhindern, wäh-

8 FAZ vom 17.02. 2007. Das Referendum bei der Ratifizierung internationaler Verträge ist in Frankreich gem. Art. 11 der Verfassung fakultativ. Die Entscheidung obliegt dem Staatspräsidenten.

9 Amtliches Endergebnis, abrufbar unter http://www.interieur.gouv.fr/sections/a_votre_service/resultatselections/PR2007/FE.html.

10 Rat der Europäischen Union: Fortführung der Vertragsreform, 10659/07 vom 14. 06. 2007.

11 Ebd., 5. 
rend Polen nicht bereit war, die Entscheidungsregel der „,doppelten Mehrheit“ für qualifizierte Mehrheitsabstimmungen im Ministerrat zu akzeptieren, da es dadurch gegenüber der geltenden Regel des Vertrags von Nizza deutlich an Einfluss verlieren würde. ${ }^{12}$

Es gelang dem Europäischen Rat schließlich, eine Einigung zu erzielen und ein umfassendes Mandat für die einzusetzende Regierungskonferenz zu beschlieBen. ${ }^{13}$ Anders als bei früheren Vertragsänderungsverfahren enthielt dieses detaillierte inhaltliche Bestimmungen. Demnach wurde die Regierungskonferenz aufgefordert, einen als „Reformvertrag“ bezeichneten Text zu erarbeiten, der - wie schon die Verträge von Amsterdam und Nizza - die Form eines Änderungsvertrages zu EUV und EGV haben sollte. Dabei wäre der bisherige EGV in „Vertrag über die Arbeitsweise der Union“ umzubenennen, wodurch der Begriff „Gemeinschaft" und mit ihm die seit Maastricht bestehende „Säulenstruktur“ der Union aufgegeben würde. Wie bereits im VVE vorgesehen, sollte die Europäische Union eine einheitliche Rechtspersönlichkeit erhalten.

Im Gegensatz zum Verfassungsvertrag sollte jedoch im Übrigen die bestehende Terminologie weitestgehend beibehalten werden, etwa bei der Bezeichnung der Rechtsakte oder dem Amt des Hohen Vertreters für die Gemeinsame Außen- und Sicherheitspolitik. ${ }^{14}$ Zudem war generell auf den Begriff „Verfassung“ zu verzichten. Symbole wie Flagge, Leitspruch und Hymne sollten ebenso unerwähnt bleiben wie die im VVE vorgesehen Feststellung des Vorrangs von Unionsrecht gegenüber mitgliedstaatlichem Recht ${ }^{15}$. All diese Maßnahmen hatten keinerlei materielle Veränderungen gegenüber dem Verfassungsvertrag zur Folge, sollten aber Befürchtungen zerstreuen, die in der Bevölkerung dem VVE entgegengebracht wurden.

Inhaltlich sollten ,die auf die RK 2004 [die Regierungskonferenz, die die Endfassung des VVE ausarbeitete, SSch] zurückgehenden Neuerungen [...] in den

12 FAZ vom 19.06. 2007.

13 Europäischer Rat (Brüssel, 21./22.06. 2007): Schlussfolgerungen des Vorsitzes, 11177/1/07 REV 1 vom 20.07. 2007, Anlage 1; siehe auch FAZ vom 25.06. 2007.

14 Der VVE sah eine Umbenennung von Verordnungen und Richtlinien in „Gesetze“ bzw. „Rahmengesetze“ vor, der Hohe Vertreter sollte die Bezeichnung „Außenminister“ tragen.

$15 \mathrm{Zu}$ dieser Frage sollte die Regierungskonferenz eine Erklärung beschließen, die auf die entsprechende ständige Rechtsprechung des Europäischen Gerichtshofs verweist. Die Regierungskonferenz kam dem nach, vgl. 17. Erklärung zum Vorrang Schlussakte der Regierungskonferenz, ABIEU Nr. C 306/256 vom 17. 12. 2007. 
EUV und den Vertrag über die Arbeitsweise der Union eingearbeitet" werden, ${ }^{16}$ Abweichungen hiervon waren im Mandat explizit aufgeführt. So sollte etwa die Charta der Grundrechte nicht in den Vertrag selbst aufgenommen werden, sondern nur auf sie verwiesen werden. Dadurch würde der Charta gleichwohl die bislang fehlende Rechtsverbindlichkeit zukommen. Das Abstimmungsverfahren mit ,doppelter Mehrheit“" sollte erst zum 1. November 2014 in Kraft treten, wobei bis zum 31. März 2017 jeder Mitgliedstaat das Recht hätte, eine Abstimmung nach dem alten Verfahren zu verlangen. Zudem würde der sog. Ioannina-Kompromiss Berücksichtigung finden, nach dem ein Beschluss verschoben wird, wenn eine Sperrminorität fast erreicht ist. Außerdem war eine weitere Stärkung der Informations- und Partizipationsrechte der nationalstaatlichen Parlamente vorgesehen sowie eine Reihe kleinerer Modifikationen in den einzelnen Politikbereichen.

Die unter portugiesischem Ratsvorsitz tagende Regierungskonferenz legte bereits am 23. Juli einen ersten, als Arbeitsgrundlage dienenden Textentwurf für den Reformvertrag vor. ${ }^{17}$ Trotz des ,engen“" Mandats wurden im Verlauf der Beratungen erneut politische Differenzen erkennbar. So forderte die polnische Außenministerin Fotyga in einem Brief an die Regierungskonferenz, dass ein Rechtsetzungsverfahren aufgrund des Ioannina-Kompromisses bis zu zwei Jahre verzögert werden könne, ${ }^{18}$ während die übrigen Mitgliedstaaten von einem Zeitraum von einigen Monaten ausgingen. Hinzu kam das britische Beharren darauf, eine Verbindlichkeit der Grundrechtecharta vor den eigenen Gerichten auszuschließen, ein Verlangen, dem sich Polen anschloss. Darüber hinaus gab es Uneinigkeit über die Sitzverteilung im Europäischen Parlament - hier bestand Italien auf einem zusätzlichen Sitz -; schließlich suchte Bulgarien, eine Festschreibung der kyrillischen Schreibweise der gemeinsamen Währung in der landessprachlichen Fassung des Vertrages zu erreichen. ${ }^{19}$

16 Europäischer Rat (Brüssel, 21./22.06. 2007), a. a. O., 16. Zu den im VVE vorgesehenen Reformen vgl. ausführlich Hesse, J.J., a. a. O., 101-126, 142-148.

17 Konferenz der Vertreter der Regierungen der Mitgliedstaaten: Entwurf eines Vertrags zur Änderung des Vertrags über die Europäische Union und des Vertrags zur Gründung der Europäischen Gemeinschaft, CIG 1/07 vom 23.07. 2007; dies.: Entwurf eines Vertrags zur Änderung des Vertrags über die Europäische Union und des Vertrags zur Gründung der Europäischen Gemeinschaft - Protokolle, CIG 2/07 vom 23.07. 2007; dies.: Entwürfe von Erklärungen, CIG 3/07 vom 23.07. 2007.

18 Conference of the Representatives of the Governments of the Member States: Statement by Ms Anna E. Fotyga, Polish Minister for Foreign Affairs, on the Occasion of the Opening of the Intergovernmental Conference, CIG 5/07 vom 25.07. 2007.

19 FAZ vom 16.10. 2007. 
Diese Fragen konnten bei der abschließenden Tagung der Regierungskonferenz auf der Ebene der Staats- und Regierungschefs in der Nacht zum 19. Oktober in Lissabon geklärt werden. Der bulgarischen Forderung wurde dabei ebenso entsprochen wie der italienischen. Um jedoch die Gesamtzahl der Abgeordneten nicht zu erhöhen, war nun vorgesehen, dass der Parlamentspräsident über kein Stimmrecht mehr verfügt. Der Ioannina-Kompromiss wurde in eine bindende Erklärung zum Vertrag aufgenommen, ohne dass die Formulierung eines ,angemessenen“ Zeitraums konkretisiert wurde. ${ }^{20}$ Ein Protokoll griff zudem die britische und polnische Forderung bezüglich der Grundrechtecharta auf. ${ }^{21}$

Die Endfassung wurde als „Vertrag von Lissabon“ am 13. Dezember von den Staats- und Regierungschefs der Mitgliedstaaten unterzeichnet. ${ }^{22}$ Die den Ratsvorsitz innehabende portugiesische Regierung hatte darauf bestanden, dass die feierliche Zeremonie in ihrer Hauptstadt stattfindet, auch wenn die anschließende Tagung des Europäischen Rates für den 14. Dezember in Brüssel anberaumt war. ${ }^{23}$ Unklar blieb bis zuletzt, ob der britische Premierminister Brown den Vertrag persönlich unterzeichnen oder es seinem Außenminister überlassen würde; schließlich tat er dies einige Stunden nach seinen Amtskollegen. ${ }^{24}$

Der Vertrag bedarf der Ratifizierung in allen Mitgliedstaaten nach nationalem Verfassungsrecht. Mit Ausnahme Irlands, wo ein Referendum zwingend vorgeschrieben ist, wird dies voraussichtlich durchwegs auf parlamentarischem Weg erfolgen. Depositarstaat für die Ratifikationsurkunden ist traditionsgemäß Italien (Art. 6 Abs. 1 Vertrag von Lissabon). Das Inkrafttreten des Vertrages ist gem. Art. 6 Abs. 2 für den 1. Januar 2009 vorgesehen, vorausgesetzt, dass zu diesem Zeitpunkt alle Ratifikationsurkunden vorliegen; anderenfalls tritt der Vertrag am ersten Tag des auf die Hinterlegung der letzten Urkunde folgenden Monats in

20 9. Erklärung zu Artikel 9c Absatz 4 des Vertrags über die Europäische Union und zu Artikel 205 Absatz 2 des Vertrags über die Arbeitsweise der Europäischen Union, Schlussakte der Regierungskonferenz, ABlEU Nr. C 306/250 vom 17. 12. 2007.

21 Protokoll über die Anwendung der Charta der Grundrechte der Europäischen Union auf Polen und das Vereinigte Königreich, ABlEU Nr. C 306/156 vom 17.12. 2007.

22 Vertrag von Lissabon zur Änderung des Vertrags über die Europäische Union und des Vertrags zur Gründung der Europäischen Gemeinschaft vom 13. 12. 2007, ABlEU Nr. C 306/1 vom 17. 12. 2007.

23 FAZ vom 14. 12. 2007.

24 Brown beabsichtigte, den Vertrag auf parlamentarischem Weg ratifizieren lassen, wohingegen sein Vorgänger Blair den VVE einem Referendum unterziehen wollte. Er begründete seine Position damit, dass die Bestimmungen des Vertrages von Lissabon deutlich weniger weitreichend seien als die des VVE. Diese Position wollte er zunächst dadurch unterstreichen, dass der Vertrag für das Vereinigte Königreich nur durch den Außenminister unterzeichnet wird. 
Kraft. In jedem Fall wird angestrebt, die Wahl zum Europäischen Parlament im Frühjahr 2009 bereits nach dem neuen Primärrecht durchzuführen.

Als erster Mitgliedstaat ratifizierte Ungarn den Vertrag am 17. Dezember 2007, also nur vier Tage nach der Unterzeichnung, durch Parlamentsbeschluss mit 325 Stimmen bei fünf Gegenstimmen und 14 Enthaltungen. ${ }^{25}$ Die übrigen Mitgliedstaaten dürften im Laufe des Jahres 2008 folgen, wobei auch bei rein parlamentarischen Verfahren erfahrungsgemäß Verzögerungen auftreten können und ein erfolgreicher Ausgang keineswegs selbstverständlich ist. Hinzu kommt als besondere Problematik das irische Referendum, zumal die dortigen Wähler bereits den Vertrag von Nizza zunächst abgelehnt hatten.

\section{Erweiterung}

Am 1. Januar 2007 wurde der Beitritt Bulgariens und Rumäniens zur Europäischen Union wirksam, die damit 27 Mitgliedstaaten umfasst. ${ }^{26}$ Auch wenn in der öffentlichen Diskussion die Stimmen zunehmen, die vor einer „Überdehnung“ der EU warnen, gilt weiterhin, dass gem. Art. 49 EUV die Mitgliedschaft grundsätzlich allen europäischen Staaten offen steht, die die Grundsätze der Union achten. Auf dieser Grundlage veröffentlichte die Kommission im November 2007 ein Strategiepapier, das an der Erweiterung als politischem Instrument uneingeschränkt festhält. ${ }^{27}$ Der Ministerrat schloss sich dem ebenso an ${ }^{28}$ wie der Europäische Rat. $^{29}$

Den formellen Status eines Beitrittskandidaten hatten im Berichtsjahr Kroatien, Mazedonien und die Türkei inne, wobei im Fall Mazedoniens bislang keine Verhandlungen stattfanden und für deren Aufnahme auch kein Termin vereinbart wurde. In ihrem Fortschrittsbericht bescheinigte die Kommission dem Land insgesamt eine weiterhin positive Entwicklung, verwies aber auf nach wie vor

25 Országgyülés: 120. ülésnap (2007.12.17.), 377; vgl. zum jeweils aktuellen Stand die Übersicht unter http://europa.eu/lisbon_treaty/countries/index_de.htm.

26 Vgl. zum Beitrittsprozess Schubert, S., a.a. O., 117 f. m.w. N.

27 Europäische Kommission: Erweiterungsstrategie und wichtigste Herausforderungen 2007-2008, KOM (2007) 663 endg. vom 06.11. 2007.

28 Rat der Europäischen Union: Schlussfolgerungen des Rates zur Erweiterung, 16365/07 vom 10.12. 2007.

29 Europäischer Rat (Brüssel, 14.12. 2007): Schlussfolgerungen des Vorsitzes, 16616/1/07 REV 1 vom 14.02. 2008, Ziff. 7. 
bestehenden erheblichen Reformbedarf. ${ }^{30}$ Schon der ökonomische Entwicklungsrückstand macht einen Beitritt in den nächsten Jahren unwahrscheinlich. Hinzu kommt die Auseinandersetzung mit dem EU-Mitglied Griechenland um das Recht zur Nutzung des Namens Mazedonien, weswegen die Union das Land weiterhin unter der vorläufigen Bezeichnung ,ehemalige jugoslawische Republik Mazedonien“ führt. Substanzielle Fortschritte in diesem seit längerem festgefahrenen Streit waren auch im Berichtsjahr nicht zu verzeichnen.

Bereits seit 2005 laufen die Beitrittsverhandlungen mit Kroatien, das unter den gegenwärtigen Kandidaten die größten Chancen auf eine baldige EU-Mitgliedschaft haben dürfte. Der Fortschrittsbericht der Kommission stellte dem Land insgesamt ein „gutes Zeugnis“ aus, mahnte aber weitere Anstrengungen insbesondere in den Bereichen der Korruptionsbekämpfung, des Minderheitenschutzes und der Übernahme des acquis communautaire an. ${ }^{31}$ Hinzu trat der fortbestehende Konflikt mit dem EU-Mitglied Slowenien über den genauen Verlauf der gemeinsamen Grenze. In dieser Angelegenheit einigten sich beide Regierungen im August, den Internationalen Gerichtshof anzurufen. ${ }^{32}$

Besonders umstritten blieb ein möglicher Beitritt der Türkei, zumal nach der deutschen Bundeskanzlerin Merkel nun mit dem neuen französischen Präsidenten Sarkozy ein weiterer Staats- bzw. Regierungschef eines großen Mitgliedstaates eine Vollmitgliedschaft des Landes ablehnte. Dessen ungeachtet wurden im Berichtsjahr die Beitrittsverhandlungen fortgeführt, wobei sie seit Dezember 2006 in einigen wesentlichen Kapiteln suspendiert waren, da die Türkei sich weigerte, die mit der Union bestehende Zollunion in vollem Unfang auch auf den EU-Mitgliedstaat Zypern auszudehnen. Im Hintergrund steht der nach wie vor ungelöste Konflikt um den Nordteil der Insel, in dem die faktische Kontrolle durch die völkerrechtlich nur von der Türkei anerkannte Türkische Republik Nordzypern ausgeübt wird. Der Rat stellte in seinen Schlussfolgerungen zur Erweiterung im Dezember 2007 fest, dass sich in dieser Frage keine Fortschritte ergeben hätten. ${ }^{33}$ Die übrigen Verhandlungskapitel sollten jeweils unmittelbar nach Erfüllung der technischen Voraussetzungen eröffnet werden; dies erfolgte im März 2007 für den Bereich Unternehmens- und Industriepolitik, im Juni für

30 European Commission: The Former Yugoslav Republic of Macedonia 2007 Progress Report, SEC (2007) 1432 vom 06.11. 2007.

31 Dies.: Croatia 2007 Progress Report, SEC (2007) 1431 vom 06. 11. 2007.

32 FAZ vom 29.08. 2007.

33 Rat der Europäischen Union: Schlussfolgerungen des Rates zur Erweiterung, a. a. O., 4. 
die Finanzkontrolle und die Statistik. ${ }^{34}$ Der Fortschrittsbericht der Kommission erkannte die Bemühungen der türkischen Regierung in vielen Bereichen an, verwies aber vor allem hinsichtlich der Demokratie und Menschenrechte auf fortbestehende erhebliche Defizite. ${ }^{35}$

Die übrigen Staaten des westlichen Balkans, also Albanien, Bosnien und Herzegowina, Montenegro sowie Serbien, gelten als potenzielle Bewerberländer. Mit Albanien besteht bereits ein Stabilisierungs- und Assoziationsabkommen, das als erster Schritt auf dem Weg zu einer Mitgliedschaft gilt. Die jeweiligen Verhandlungen mit den übrigen genannten Staaten dauerten im Berichtsjahr an. Im Fall Serbiens wurden diese am 13. Juni wieder aufgenommen, nachdem sie im Vorjahr (noch mit dem Vorgängerstaat Serbien und Montenegro) aufgrund mangelnder Kooperation mit dem Internationalen Strafgerichtshof für das frühere Jugoslawien suspendiert worden waren. ${ }^{36}$ Hinzu kam als Sonderfall das Kosovo, das im Berichtsjahr de jure als Teil Serbiens galt, de facto aber unter Kontrolle der Vereinten Nationen stand. Für das Jahr 2008 wurde eine Unabhängigkeitserklärung erwartet. In allen genannten Fällen dürfte ein Beitritt zur Union schon aufgrund der erheblichen politischen, ökonomischen und rechtlich-administrativen Rückstände in weiter Ferne liegen.

\section{Aus den Politikbereichen}

\section{Binnenmarkt}

Nach dem Beitritt Bulgariens und Rumäniens bleibt der Zugang von deren Staatsangehörigen $z u$ den Arbeitsmärkten der bisherigen EU-Staaten noch für eine mehrjährige Übergangszeit beschränkt. Es wurde den alten Mitgliedstaaten anheimgestellt, die Öffnung ihres Arbeitsmarktes in drei Phasen bis höchstens Ende 2013 zu verzögern. Zehn Länder (Finnland, Schweden sowie die 2004 beigetretenen Staaten außer Malta und Ungarn) verzichteten darauf, in den übrigen Staaten unterliegt der Zugang bulgarischer und rumänischer Staatsangehöriger zum nationalen Arbeitsmarkt je spezifischen Hürden, die erstmals Ende 2008 überprüft werden sollen. Die beiden Beitrittsstaaten haben ihrerseits keinen Ge-

34 http://ec.europa.eu/enlargement/turkey/key_events_en.htm.

35 European Commission: Turkey 2007 Progress Report, SEC (2007) 1436 vom 06. 11. 2007.

36 http://ec.europa.eu/enlargement/serbia/key_events_en.htm. 
brauch von der Möglichkeit gemacht, die Freizügigkeit für Arbeitnehmer aus den alten Mitgliedstaaten zu beschränken. ${ }^{37}$

Auch für die Staatsangehörigen der acht 2004 beigetretenen mittel- und osteuropäischen Staaten bestehen in einer Reihe alter Mitgliedstaaten weiterhin entsprechende Beschränkungen, namentlich in Belgien, Dänemark, Deutschland, Frankreich und Österreich. Die Niederlande hoben ihre Restriktionen zum 1. Mai 2007 auf, Luxemburg folgte zum 1. November. Unter den Beitrittstaaten wendete Ungarn dabei das Gegenseitigkeitsprinzip gegenüber den jeweiligen alten Mitgliedstaaten an; Polen verzichtete darauf zum 17. Januar 2007. Die nächste allgemeine Überprüfung der Beschränkungen ist zum 1. Mai 2009 vorgesehen, dann ist eine letztmalige Verlängerung bis 30. April 2011 möglich. ${ }^{38}$

Fortschritte machte im Berichtsjahr die Beratung des Richtlinienvorschlags zur Liberalisierung des Marktes für Postdienstleistungen. ${ }^{39}$ Das Parlament befürwortete am 11. Juli in erster Lesung den Kommissionsentwurf, verlangte jedoch einige Änderungen, die insbesondere den Nutzen für Verbraucher und kleine und mittlere Unternehmen sowie die Sicherstellung der Versorgung im ländlichen Raum betrafen. ${ }^{40}$ Der Rat erzielte am 1. Oktober eine politische Einigung über einen gemeinsamen Standpunkt, wonach die bestehenden Briefmonopole nicht, wie von der Kommission vorgeschlagen, zu Beginn des Jahres 2009, sondern erst zum 31. Dezember 2010 auslaufen sollten; zudem wurde elf Mitgliedstaaten die Möglichkeit eingeräumt, diese Frist um bis zu zwei Jahre zu überschreiten. ${ }^{41}$ Der Rat nahm diesen Standpunkt am 8. November mit qualifizierter Mehrheit gegen die Stimmen Luxemburgs bei Enthaltung Belgiens an, ${ }^{42}$ die Kommission

37 http://ec.europa.eu/employment_social/free_movement/enlargement_de.htm.

38 Ebd.

39 Europäische Kommission: Vorschlag für eine Richtlinie des Europäischen Parlaments und des Rates zur Änderung der Richtlinie 97/67/EG über die Vollendung des Binnenmarkts für Postdienste, KOM (2006) 594 endg. vom 18. 10. 2006.

40 Europäisches Parlament: Legislative Entschließung des Europäischen Parlaments zu dem Vorschlag für eine Richtlinie des Europäischen Parlaments und des Rates zur Änderung der Richtlinie 97/67/EG über die Vollendung des Binnenmarktes für Postdienste, P6_TA(2007)0336 vom 11.07. 2007.

41 Rat der Europäischen Union: Mitteilung an die Presse. 2821. Tagung des Rates. Verkehr, Telekommunikation, Energie, C/07/203 vom 01.10. 2007, 8.

42 Ders.: Mitteilung an die Presse. 2827. Tagung des Rates. Justiz und Inneres, C/07/253 vom 08.11. 2007, 39; ders.: Gemeinsamer Standpunkt des Rates vom 8. November 2007 im Hinblick auf den Erlass der Richtlinie des Europäischen Parlaments und des Rates zur Änderung der Richtlinie 97/67/EG im Hinblick auf die Vollendung des Binnenmarktes für Postdienste in der Gemeinschaft, 13593/6/07 REV 6 vom 08. 11. 2007. 
billigte ihn am folgenden Tag. ${ }^{43}$ Zum Abschluss des Rechtsetzungsverfahrens bedurfte es noch der Zustimmung des Parlaments zum geänderten Text.

Besondere Aufmerksamkeit erfuhr weiterhin der Bereich der Finanzdienstleistungen. Das Parlament billigte am 24. April eine Richtlinie zum Zahlungsverkehr mit dem Ziel der Schaffung eines einheitlichen europäischen Zahlungsraums bis $2010{ }^{44}$ Nach Annahme dieser Fassung durch den Rat am 15. Oktober ${ }^{45}$ konnte die Richtlinie am 13. November unterzeichnet werden. ${ }^{46}$ Hinzu kam seitens der Kommission die Annahme eines Weißbuchs zur Integration der Hypothekarkreditmärkte. $^{47}$

Auf dem Gebiet des Gesellschaftsrechts wurden zwei Richtlinien zur Harmonisierung der Verfahren in Aktiengesellschaften erlassen. ${ }^{48}$ Darüber hinaus forderte das Parlament die Kommission auf, einen Legislativvorschlag für ein Statut der Europäischen Privatgesellschaft („Europa-GmbH“) auszuarbeiten. ${ }^{49}$ Die Kommission steht dem bislang skeptisch gegenüber; im Berichtsjahr führte sie eine Konsultation von Unternehmen durch, wonach drei Viertel der Antwortenden die Notwendigkeit eines solchen Statuts befürworteten, da die unterschiedli-

43 Europäische Kommission: Mitteilung der Kommission an das Europäische Parlament gemäß Artikel 251 Absatz 2 Unterabsatz 2 EG-Vertrag zum gemeinsamen Standpunkt des Rates betreffend den Erlass der Richtlinie des Europäischen Parlaments und des Rates zur Änderung der Richtlinie 97/67/EG im Hinblick auf die Vollendung des Binnenmarktes für Postdienste in der Gemeinschaft, KOM (2007) 695 endg. vom 09.11. 2007.

44 Europäisches Parlament: Legislative Entschließung des Europäischen Parlaments zu dem Vorschlag für eine Richtlinie des Europäischen Parlaments und des Rates über Zahlungsdienste im Binnenmarkt und zur Änderung der Richtlinien 97/7/EG, 2000/12/EG und 2002/65/EG, P6_TA(2007)0128 vom 24.04. 2007.

45 Rat der Europäischen Union: Mitteilung an die Presse. 2823. Tagung des Rates. Allgemeine Angelegenheiten und Außenbeziehungen, C/07/236 vom 15. 10. 2007, 13.

46 Richtlinie 2007/64/EG des Europäischen Parlaments und des Rates vom 13.11. 2007 über Zahlungsdienste im Binnenmarkt, zur Änderung der Richtlinien 97/7/EG, 2002/65/EG, 2005/60/EG und 2006/ 48/EG sowie zur Aufhebung der Richtlinie 97/5/EG, ABlEU Nr. L 319/1 vom 05. 12. 2007.

47 Europäische Kommission: Weißbuch über die Integration der EU-Hypothekarkreditmärkte, KOM (2007) 807 endg. vom 18. 12. 2007.

48 Richtlinie 2007/36/EG des Europäischen Parlaments und des Rates vom 11.07. 2007 über die Ausübung bestimmter Rechte von Aktionären in börsennotierten Gesellschaften, ABlEU Nr. L 184/17 vom 14.07. 2007; Richtlinie 2007/63/EG des Europäischen Parlaments und des Rates vom 13.11. 2007 zur Änderung der Richtlinien 78/855/EWG und 82/891/EWG des Rates hinsichtlich des Erfordernisses der Erstellung eines Berichts durch einen unabhängigen Sachverständigen anlässlich der Verschmelzung oder der Spaltung von Aktiengesellschaften, ABlEU Nr. L 300/47 vom 17. 11. 2007.

49 Europäisches Parlament: Entschließung des Europäischen Parlaments mit Empfehlungen an die Kommission zum Statut der Europäischen Privatgesellschaft, P6_TA(2007)0023 vom 01.02. 2007. 
chen nationalen gesellschaftsrechtlichen Vorgaben grenzüberschreitende Aktivitäten erschwerten. ${ }^{50}$

\section{Landwirtschaft und Fischerei}

Die Entwicklung im Bereich Landwirtschaft war 2007 in der öffentlichen Wahrnehmung maßgeblich durch gestiegene Verbraucherpreise vor allem bei Milchprodukten geprägt; daraus leiteten sich Forderungen nach einer Liberalisierung der Gemeinsamen Agrarpolitik, insbesondere einer Erhöhung bzw. Abschaffung der Milchquoten, $a b .{ }^{51}$ Rechtliche Maßnahmen dazu folgten zunächst nicht, die Kommission empfahl allerdings Ende des Jahres in einem Bericht an den Rat eine Erhöhung der Milchquote um 2\% vor dem Hintergrund der gestiegenen Nachfrage. ${ }^{52}$ Darüber hinaus wurden durch eine Reform der Gemeinsamen Marktordnung für Getreide Höchstmengen für den von den Interventionsstellen anzukaufenden Mais eingeführt, die bis 2009 stufenweise auf null abgesenkt werden. ${ }^{53}$

Aus der Gemeinsamen Fischereipolitik sind neben einigen Anpassungen der Regelungen für einzelne Fischarten und Fanggebiete ${ }^{54}$ fortgesetzte Bemühungen zu verstärkter Nachhaltigkeit zu verzeichnen. Dazu verabschiedete der Rat eine Verordnung, die der Verbesserung von Sicherheit, Hygiene, Arbeitsbedingungen und Produktqualität an Bord der Schiffe sowie der Modernisierung der Motoren dienen soll. ${ }^{55}$ Hinzu kam ein Verordnungsvorschlag der Kommission zur Bekämpfung der illegalen Fischerei. ${ }^{56}$

50 European Commission: Synthesis of the Comments on the Consultation Document of the Internal Market and Services Directorate-General on a Possible Statute for a European Private Company, Brüssel, 2007; vgl. auch FAZ vom 14.08. 2007.

51 Vgl. FAZ vom 29.06. 2007 und vom 31.07. 2007.

52 Europäische Kommission: Marktperspektiven für den Milchsektor, KOM (2007) 800 endg. vom 12. 12. 2007.

53 Verordnung (EG) Nr. 735/2007 des Rates vom 11.06. 2007 zur Änderung der Verordnung (EG) Nr. 1784/2003 über die gemeinsame Marktorganisation für Getreide, ABIEU Nr. L 169/6 vom 29.06. 2007.

54 Vgl. dazu Europäische Kommission: Gesamtbericht über die Tätigkeit der Europäischen Union 2007, Brüssel/Luxemburg, 2008, $130 \mathrm{f}$.

55 Verordnung (EG) Nr. 865/2007 des Rates vom 10.07. 2007 zur Änderung der Verordnung (EG) Nr. 2371/2002 über die Erhaltung und nachhaltige Nutzung der Fischereiressourcen im Rahmen der gemeinsamen Fischereipolitik, ABlEU Nr. L 192/1 vom 24.07. 2007.

56 Europäische Kommission: Vorschlag für eine Verordnung des Rates über ein Gemeinschaftssystem zur Verhinderung, Bekämpfung und Unterbindung der illegalen, nicht gemeldeten und unregulierten Fischerei, KOM (2007) 602 endg. vom 17. 10. 2007. 


\section{Visa, Asyl, Einwanderung}

Nachdem die 2004 und 2007 beigetretenen neuen Mitgliedstaaten zunächst noch nicht in den sog. Schengen-Raum ohne Personenkontrollen an den Binnengrenzen einbezogen worden waren, stellte der Rat am 8. November fest, dass die Staaten der Erweiterungsrunde von 2004 mit Ausnahme Zyperns ausreichend vorbereitet seien, die Bestimmungen des gesamten Schengen-Besitzstands ,in zufrieden stellender Weise anzuwenden ${ }^{\text {‘57 }}$. Daraufhin fasste er am 6. Dezember den formellen Beschluss, die Kontrollen mit und zwischen diesen Staaten an den Land- und Seegrenzen zum 21. Dezember 2007 aufzuheben, an den Luftgrenzen zum 30. März 2008. ${ }^{58}$

Im Rahmen des Unionsprogramms ,,Solidarität und Steuerung der Flüchtlingsströme" wurden mehrere gemeinschaftliche Fonds zur Unterstützung der Mitgliedstaaten im Rahmen der Migrationspolitik eingerichtet: der Außengrenzenfonds, der Europäische Flüchtlingsfonds, der Europäische Rückkehrfonds sowie der Europäische Fonds für die Integration von Drittstaatsangehörigen. ${ }^{59}$

Am 1. Juni 2007 traten die im Vorjahr unterzeichneten Abkommen mit Russland über eine erleichterte Ausstellung von Kurzzeit-Visa sowie über die Rückführung illegal eingereister Personen in Kraft. ${ }^{60}$ Entsprechende Abkommen wurden

57 Rat der Europäischen Union: Mitteilung an die Presse. 2827. Tagung des Rates. Justiz und Inneres, 14617/07 vom 08. 11. 2007, 26.

58 2007/801/EG: Beschluss des Rates vom 06.12. 2007 über die vollständige Anwendung der Bestimmungen des Schengen-Besitzstands in der Tschechischen Republik, der Republik Estland, der Republik Lettland, der Republik Litauen, der Republik Ungarn, der Republik Malta, der Republik Polen, der Republik Slowenien und der Slowakischen Republik, ABIEU Nr. L 323/34 vom 08. 12. 2007.

59 Entscheidung Nr. 574/2007/EG des Europäischen Parlaments und des Rates vom 23.05. 2007 zur Einrichtung des Außengrenzenfonds für den Zeitraum 2007 bis 2013 innerhalb des Generellen Programms Solidarität und Steuerung der Migrationsströme, ABlEU Nr. L 144/22 vom 06.06. 2007; Entscheidung Nr. 573/2007/EG des Europäischen Parlaments und des Rates vom 23.05. 2007 zur Einrichtung des Europäischen Flüchtlingsfonds für den Zeitraum 2008 bis 2013 innerhalb des Generellen Programms Solidarität und Steuerung der Migrationsströme und zur Aufhebung der Entscheidung 2004/904/EG des Rates, ABIEU Nr. L 144/1 vom 06.06. 2007; Entscheidung Nr. 575/2007/EG des Europäischen Parlaments und des Rates vom 23.05. 2007 zur Einrichtung des Europäischen Rückkehrfonds für den Zeitraum 2008 bis 2013 innerhalb des Generellen Programms Solidarität und Steuerung der Migrationsströme, ABlEU Nr. L 144/45 vom 06.06. 2007; 2007/435/EG: Entscheidung des Rates vom 25.06. 2007 zur Einrichtung des Europäischen Fonds für die Integration von Drittstaatsangehörigen für den Zeitraum 2007 bis 2013 innerhalb des Generellen Programms Solidarität und Steuerung der Migrationsströme, ABIEU Nr. L 168/18 vom 28.06. 2007.

60 2007/340/EG: Beschluss des Rates vom 19.04. 2007 über den Abschluss des Abkommens zwischen der Europäischen Gemeinschaft und der Russischen Föderation über die Erleichterung der Ausstellung von Visa für einen kurzfristigen Aufenthalt, ABlEU Nr. L 129/25 vom 17.05. 2007 sowie Mitteilung über das Inkrafttreten des Abkommens zwischen der Europäischen Gemeinschaft und der Russischen 


\section{im Laufe des Jahres auch mit Albanien (kein Rückführungsabkommen), Bosnien und Herzegowina, Mazedonien, Moldau, Montenegro, Serbien und der Ukraine unterzeichnet; der Rat billigte sie im November, das Inkrafttreten war für den 1. Januar 2008 vorgesehen. ${ }^{61}$}

Föderation über die Erleichterung der Ausstellung von Visa für Bürger der Europäischen Union und für Staatsangehörige der Russischen Föderation, ABIEU Nr. L 173/34 vom 03.07. 2007; 2007/341/EG: Beschluss des Rates vom 19.04. 2007 über den Abschluss des Rückübernahmeabkommens zwischen der Europäischen Gemeinschaft und der Russischen Föderation, ABlEU Nr. L 129/38 vom 17.05. 2007 sowie Mitteilung über das Inkrafttreten des Rückübernahmeabkommens zwischen der Europäischen Gemeinschaft und der Russischen Föderation, ABlEU Nr. L 156/37 vom 16. 06. 2007.

61 2007/821/EG: Beschluss des Rates vom 08.11. 2007 über den Abschluss des Abkommens zwischen der Europäischen Gemeinschaft und der Republik Albanien zur Erleichterung der Visaerteilung, ABlEU Nr. L 334/84 vom 19. 12. 2007; 2007/822/EG: Beschluss des Rates vom 08.11. 2007 über den Abschluss des Abkommens zwischen der Europäischen Gemeinschaft und Bosnien und Herzegowina zur Erleichterung der Visaerteilung, ABIEU Nr. L 334/96 vom 19. 12. 2007; 2007/820/EG: Beschluss des Rates vom 08. 11. 2007 über den Abschluss des Abkommens zwischen der Europäischen Gemeinschaft und Bosnien und Herzegowina über die Rückübernahme von Personen mit unbefugtem Aufenthalt, ABlEU Nr. L 334/65 vom 19.12. 2007; 2007/824/EG: Beschluss des Rates vom 08. 11. 2007 über den Abschluss des Abkommens zwischen der Europäischen Gemeinschaft und der ehemaligen jugoslawischen Republik Mazedonien zur Erleichterung der Visaerteilung - Briefwechsel, ABlEU Nr. L 334/120 vom 19. 12. 2007; 2007/817/EG: Beschluss des Rates vom 08.11. 2007 über den Abschluss des Abkommens zwischen der Europäischen Gemeinschaft und der ehemaligen jugoslawischen Republik Mazedonien über die Rückübernahme von Personen mit unbefugtem Aufenthalt - Briefwechsel, ABIEU Nr. L 334/1 vom 19. 12. 2007; 2007/827/EG: Beschluss des Rates vom 22.11. 2007 über den Abschluss des Abkommens zwischen der Europäischen Gemeinschaft und der Republik Moldau über Erleichterungen bei der Erteilung von Visa, ABIEU Nr. L 334/168 vom 19. 12. 2007; 2007/826/EG: Beschluss des Rates vom 22. 11. 2007 über den Abschluss des Abkommens zwischen der Europäischen Gemeinschaft und der Republik Moldau über die Rückübernahme von Personen mit unbefugtem Aufenthalt, ABIEU Nr. L 334/148 vom 19. 12. 2007; 2007/823/EG: Beschluss des Rates vom 08. 11. 2007 über den Abschluss des Abkommens zwischen der Europäischen Gemeinschaft und der Republik Montenegro zur Erleichterung der Visaerteilung, ABIEU Nr. L 334/108 vom 19.12. 2007; 2007/818/EG: Beschluss des Rates vom 08. 11. 2007 über den Abschluss des Abkommens zwischen der Europäischen Gemeinschaft und der Republik Montenegro über die Rückübernahme von Personen mit unbefugtem Aufenthalt, ABIEU Nr. L 334/25 vom 19.12. 2007; 2007/825/EG: Beschluss des Rates vom 08.11. 2007 über den Abschluss des Abkommens zwischen der Europäischen Gemeinschaft und der Republik Serbien zur Erleichterung der Visaerteilung, ABlEU Nr. L 334/136 vom 19. 12. 2007; 2007/819/EG: Beschluss des Rates vom 08. 11. 2007 über den Abschluss des Abkommens zwischen der Europäischen Gemeinschaft und der Republik Serbien über die Rückübernahme von Personen mit unbefugtem Aufenthalt, ABlEU Nr. L 334/45 vom 19.12. 2007; 2007/840/EG: Beschluss des Rates vom 29.11. 2007 über den Abschluss des Abkommens zwischen der Europäischen Gemeinschaft und der Ukraine über Erleichterungen bei der Erteilung von Visa, ABIEU Nr. L 332/66 vom 18. 12. 2007; 2007/839/EG: Beschluss des Rates vom 29.11. 2007 über den Abschluss des Abkommens zwischen der Europäischen Gemeinschaft und der Ukraine über die Rückübernahme von Personen, ABIEU Nr. L 332/46 vom 18. 12. 2007. 


\section{Verkehr}

Im Oktober verabschiedeten Parlament und Rat das dritte Eisenbahnpaket, das insbesondere eine Verordnung zur Stärkung der Rechte von Passagieren im Personenverkehr beinhaltet; ${ }^{62}$ hinzu kamen zwei Richtlinien zur Marktöffnung und Rechtsvereinheitlichung. ${ }^{63}$

Vorangetrieben wurde auch die Entwicklung des neuen Flugmanagementsystems SESAR, das die nach wie vor mannigfaltigen Effizienzprobleme in der Regulierung des Luftraums beheben soll. Hierzu beschloss der Rat im Februar die Errichtung eines eigenen Unternehmens; ${ }^{64}$ die Kommission veröffentlichte im März einen Bericht über den Fortschritt des Projekts. ${ }^{65}$ Die Einführung des neuen Systems soll im Zeitraum von 2014 bis 2020 erfolgen. Insgesamt macht die Vereinheitlichung des europäischen Luftraums nach Ansicht der Kommission bislang nur unzureichende Fortschritte. ${ }^{66}$

Mit den Vereinigten Staaten wurde am 30. April ein Luftverkehrsabkommen unterzeichnet, durch das die bislang bestehenden Beschränkungen im transatlantischen Luftverkehr aufgehoben werden. Europäische und amerikanische Fluggesellschaften können damit ohne Beschränkungen Flüge zwischen den USA und der EU anbieten. Das Inkrafttreten des Abkommens steht noch aus, es soll im gegenseitigen Einvernehmen ab dem 30. März 2008 zunächst vorläufig angewendet werden. ${ }^{67}$

62 Verordnung (EG) Nr. 1371/2007 des Europäischen Parlaments und des Rates vom 23.10. 2007 über die Rechte und Pflichten der Fahrgäste im Eisenbahnverkehr, ABIEU Nr. L 315/14 vom 03. 12. 2007.

63 Richtlinie 2007/58/EG des Europäischen Parlaments und des Rates vom 23.10. 2007 zur Änderung der Richtlinie 91/440/EWG des Rates zur Entwicklung der Eisenbahnunternehmen der Gemeinschaft sowie der Richtlinie 2001/14/EG über die Zuweisung von Fahrwegkapazität der Eisenbahn und die Erhebung von Entgelten für die Nutzung von Eisenbahninfrastruktur, ABIEU Nr. L 315/44 vom 03. 12. 2007; Richtlinie 2007/59/EG des Europäischen Parlaments und des Rates vom 23.10. 2007 über die Zertifizierung von Triebfahrzeugführern, die Lokomotiven und Züge im Eisenbahnsystem in der Gemeinschaft führen, ABIEU Nr. L 315/51 vom 03. 12. 2007.

64 Verordnung (EG) Nr. 219/2007 des Rates vom 27.02. 2007 zur Gründung eines gemeinsamen Unternehmens zur Entwicklung des europäischen Flugverkehrsmanagementsystems der neuen Generation (SESAR), ABIEU Nr. L 64/1 vom 02.03. 2007.

65 Europäische Kommission: Stand des Vorhabens zur Errichtung des europäischen Flugverkehrsmanagementsystems der neuen Generation (SESAR), KOM (2007) 103 endg. vom 15.03. 2007.

66 Dies.: Schaffung des einheitlichen europäischen Luftraums durch funktionelle Luftraumblöcke: Sachstandsbericht zur Halbzeit, KOM (2007) 101 endg. vom 15.03. 2007.

67 2007/339/EG: Beschluss des Rates und der im Rat vereinigten Vertreter der Regierungen der Mitgliedstaaten der Europäischen Union vom 25.04. 2007 über die Unterzeichnung und vorläufige Anwendung 


\section{Wettbewerb}

Auch im Jahr 2007 wirkte die Kommission in ihrer Rolle als Wettbewerbshüterin und verhängte Kartellstrafen in einer Gesamthöhe von 3,33 Mrd. $€ .{ }^{68}$ Gegen die ehemals staatliche spanische Telefongesellschaft Telefónica erging eine Geldbuße wegen überhöhter Preise unter Ausnutzung einer marktbeherrschenden Stellung in Höhe von 151 Mio. $€ .^{69}$

Auf dem Gebiet der Fusionskontrolle wurden nach Angaben der Kommission $97 \%$ der angemeldeten Zusammenschlüsse genehmigt. ${ }^{70}$ Untersagt wurde jedoch die Übernahme der irischen Fluggesellschaft Aer Lingus durch Ryanair, da so auf 35 Strecken ein Monopol bzw. eine marktbeherrschende Stellung entstanden wäre. ${ }^{71}$ Nur unter teils erheblichen Auflagen genehmigt wurden die Übernahme von Télé2 France durch SFR im Telekommunikationsbereich, der Kauf eines Teils des Spanplattengeschäfts des österreichischen Herstellers Constantia durch das deutsche Unternehmen Kronospan sowie die Fusion des Tonträgergeschäfts von Sony und BMG. ${ }^{72}$

Für Aufsehen sorgten die Maßnahmen der spanischen Regierung, die Übernahme des heimischen Energieversorgers Endesa durch den deutschen Konkurrenten Eon zu verhindern. Die Kommission beschloss im Januar, Spanien wegen unzulässiger Einschränkung des freien Kapitalverkehrs und der Niederlassungsfreiheit vor dem Europäischen Gerichtshof zu verklagen. ${ }^{73}$ Wegen der anhaltenden spanischen Widerstände erklärte Eon am 2. April, das Vorhaben nicht weiterzu-

des Luftverkehrsabkommens zwischen der Europäischen Gemeinschaft und ihren Mitgliedstaaten einerseits und den Vereinigten Staaten von Amerika andererseits, ABIEU Nr. L 134/1 vom 25.05. 2007.

71 Dies.: Fusionskontrolle: Kommission untersagt geplante Übernahme von Air Lingus durch Ryanair, IP/ 07/893 vom 27.06. 2007.

72 Dies.: Fusionen: Kommission genehmigt Übernahme von Télé2 France durch SFR mit Auflagen, IP/ 07/1120 vom 18.07. 2007; dies.: Fusionskontrolle: Kommission genehmigt unter Auflagen Übernahme eines Teils der Spanplattensparte von Constantia durch die Kronospan-Gruppe, IP/07/1360 vom 19.09. 2007; dies.: Fusionskontrolle: Kommission bestätigt Genehmigung des Tonträger-Joint-Ventures von Sony und BMG, IP/07/1437 vom 03. 10. 2007.

73 Dies.: Freier Kapitalverkehr: Kommission verklagt Spanien vor dem Europäischen Gerichtshof wegen Gesetzes, das die Aufgaben der spanischen Strom- und Gasregulierungsbehörde erweitert, IP/07/82 vom 24.01. 2007. 
verfolgen. ${ }^{74}$ Dessen ungeachtet reichte die Kommission am 11. April ihre Klage im Vertragsverletzungsverfahren ein; eine Entscheidung stand zum Ende des Berichtsjahrs noch aus. ${ }^{75}$

\section{Wirtschafts- und Währungspolitik}

Auf seiner Tagung im März hob der Europäische Rat den Beitrag der LissabonStrategie für Wachstum und Beschäftigung zum gesamtwirtschaftlichen Aufschwung und zur Erhöhung des Beschäftigungsniveaus in der Union hervor und lobte die Anstrengungen der Mitgliedstaaten auf der Grundlage der nationalen Reformprogramme. ${ }^{76}$ Für den 2008 in diesem Rahmen beginnenden neuen Dreijahreszyklus erarbeitete die Kommission einen Strategiebericht, der auch eine Halbzeitbilanz seit der Reform 2005 enthielt. $^{77}$ Dieser Bericht wurde vom Europäischen Rat auf seiner Tagung im Dezember begrüßt; er rief dazu auf, die vorgeschlagenen Maßnahmen zügig umzusetzen. ${ }^{78}$

Durch den allgemeinen wirtschaftlichen Aufschwung verbesserte sich die Lage der öffentlichen Haushalte spürbar, so dass mehrere Defizitverfahren im Rahmen des Stabilitäts- und Wachstumspaktes im Berichtsjahr beendet werden konnten. Dies betraf Deutschland, Frankreich, Griechenland, Malta und das Vereinigte Königreich. ${ }^{79}$ Damit waren noch Defizitverfahren gegen Italien, Polen, Portugal,

74 FAZ vom 03.04. 2007.

75 EuGH, Rs. C-196/07.

76 Europäischer Rat (Brüssel, 08./09. 03. 2007): Schlussfolgerungen des Vorsitzes, 7224/1/07 REV 1 vom 02.05. 2007, Ziff. $1 \mathrm{ff}$.

77 Europäische Kommission: Strategiebericht zur erneuerten Lissabon-Strategie für Wachstum und Beschäftigung: Eintritt in den neuen Programmzyklus (2008-2010) - Das Tempo der Reformen beibehalten, KOM (2007) 803 endg. vom 11.12. 2007.

78 Europäischer Rat (Brüssel, 14. 12. 2007), a. a. O., Ziff. $38 \mathrm{ff}$.

79 2007/490/EG: Entscheidung des Rates vom 05.06. 2007 zur Aufhebung der Entscheidung 2003/89/EG über das Bestehen eines übermäßigen Defizits in Deutschland, ABlEU Nr. L 183/23 vom 13.07. 2007; 2007/154/EG: Entscheidung des Rates vom 30.01. 2007 zur Aufhebung der Entscheidung 2003/487/ EG über das Bestehen eines übermäßigen Defizits in Frankreich, ABIEU Nr. L 68/3 vom 08. 03. 2007; 2007/465/EG: Entscheidung des Rates vom 05.06. 2007 zur Aufhebung der Entscheidung 2004/917/ EG über das Bestehen eines übermäßigen Defizits in Griechenland, ABlEU Nr. L 176/21 vom 06.07. 2007; 2007/464/EG: Entscheidung des Rates vom 05.06. 2007 zur Aufhebung der Entscheidung 2005/ 186/EG über das Bestehen eines übermäßigen Defizits in Malta, ABlEU Nr. L 176/19 vom 06.07. 2007; 2007/738/EG: Entscheidung des Rates vom 09. 10. 2007 zur Aufhebung der Entscheidung 2006/ 125/EG über das Bestehen eines übermäßigen Defizits im Vereinigten Königreich, ABIEU Nr. L 300/ 49 vom 17.11. 2007. 
die Slowakei, Tschechien und Ungarn anhängig. Neue Verfahren wurden im Berichtsjahr nicht eingeleitet. ${ }^{80}$

Zum 1. Januar 2007 wurde Slowenien als erster Staat der EU-Osterweiterung in die Europäische Währungsunion aufgenommen ${ }^{81}$ die Kommission stellte im Rückblick fest, die Umstellung sei rasch und reibungslos abgelaufen. ${ }^{82}$ Unter den übrigen Beitrittstaaten strebten Malta und Zypern eine Einführung der Gemeinsamen Währung zum 1. Januar 2008 an, die Slowakei zum 1. Januar 2009. Rumänien nannte das Jahr 2014, alle weiteren Staaten hatten keinen konkreten Zieltermin festgelegt. ${ }^{83}$ Für Malta und Zypern legte die Kommission im Mai positive Konvergenzberichte vor; ${ }^{84}$ auf dieser Grundlage beschloss der Rat im Juli, den Euro in beiden Ländern wie angestrebt mit Beginn des Jahres 2008 einzuführen. ${ }^{85}$ Damit wird sich die Euro-Gruppe auf 15 Staaten erhöhen.

\section{Gemeinsame Handelspolitik und Zollunion}

Die Union war im Jahr 2007 an insgesamt 31 Streitbeilegungsverfahren im Rahmen der Welthandelsorganisation (WTO) beteiligt, in elf davon stand sie den USA gegenüber. ${ }^{86}$ Mit Russland und der Ukraine wurden für den Zeitraum bis zum Beitritt beider Staaten zur WTO jeweils gesonderte Abkommen über den Handel mit Stahlerzeugnissen geschlossen. ${ }^{87}$

80 http://ec.europa.eu/economy_finance/sg_pact_fiscal_policy/excessive_deficit9109_en.htm.

81 Zum Verfahren vgl. Schubert, S., a. a. O., $133 \mathrm{f}$.

82 Europäische Kommission: Die Einführung des Euro in Slowenien, KOM (2007) 233 endg. vom 04. 05. 2007.

83 Dies.: Fünfter Bericht über die praktischen Vorbereitungen für die künftige Erweiterung des Eurogebiets, KOM (2007) 434 endg. vom 16.07. 2007, 3.

84 Dies.: Konvergenzbericht 2007 zu Malta, KOM (2007) 258 endg. vom 16.05. 2007; dies.: Konvergenzbericht Zypern 2007, KOM (2007) 255 endg. vom 16.05. 2007.

85 2007/504/EG: Entscheidung des Rates vom 10.07. 2007 gemäß Artikel 122 Absatz 2 des Vertrags über die Einführung der einheitlichen Währung durch Malta am 1. Januar 2008, ABIEU Nr. L 186/32 vom 18.07. 2007; 2007/503/EG: Entscheidung des Rates vom 10.07. 2007 gemäß Artikel 122 Absatz 2 des Vertrags über die Einführung der einheitlichen Währung durch Zypern am 1. Januar 2008, ABIEU Nr. L 186/29 vom 18.07.2007. Vgl. zu Einzelheiten der Einführung auch Europäische Kommission: Sechster Bericht über die praktischen Vorbereitungen für die künftige Erweiterung des Eurogebiets, KOM (2007) 759 endg. vom 27.11. 2007.

86 Dies.: Gesamtbericht, a.a. O., 183.

87 2007/739/EG: Beschluss des Rates vom 22.10. 2007 über den Abschluss eines Abkommens zwischen der Europäischen Gemeinschaft und der Russischen Föderation über den Handel mit bestimmten Stahlerzeugnissen, ABIEU Nr. L 300/51 vom 17.11. 2007; 2007/451/EG: Beschluss des Rates vom 30.05. 2007 über den Abschluss des Abkommens zwischen der Europäischen Gemeinschaft und der Regie- 
Zur Unterstützung der Zollbehörden wurde das Aktionsprogramm „Zoll 2013“ mit einem Volumen von 323,8 Mio. $€$ beschlossen. ${ }^{88}$ Zudem stimmte der Rat dem Beitritt der Gemeinschaft zur Weltzollorganisation (WZO) zu; bis zum Vorliegen der rechtlichen Voraussetzungen seitens der WZO sollen die Rechte und Pflichten der Mitgliedstaaten ad interim durch die Gemeinschaft wahrgenommen werden. ${ }^{89}$

\section{Beschäftigungs- und Sozialpolitik}

Der im Vorjahr eingerichtete Europäische Fonds für die Anpassung an die Globalisierung wurde 2007 erstmals in Anspruch genommen. Für Maßnahmen zugunsten entlassener Arbeiter bei Zulieferern von Peugeot und Renault in Frankreich wurden 3,8 Mio. $€$ bewilligt, zur Milderung der Folgen von Massenentlassungen bei Herstellern von Mobiltelefonen (BenQ in Deutschland und Perlos in Finnland) 14,8 Mio. $€^{90}$

\section{Bildung}

Das Rechtsetzungsverfahren zur Errichtung des Europäischen Technologieinstituts machte 2007 erkennbare Fortschritte. Das Parlament billigte im September in erster Lesung den Verordnungsvorschlag der Kommission mit Änderungen, die vor allem die Autonomie der Einrichtung und der in diesem Rahmen vorgesehenen Wissens- und Innovationsgemeinschaften betrafen. Hinzu kam die Forderung, in die Bezeichnung der Einrichtung den Begriff der „Innovation“ aufzu-

rung der Ukraine über den Handel mit bestimmten Stahlerzeugnissen, ABlEU Nr. L 178/22 vom 06.07. 2007.

88 Entscheidung Nr. 624/2007/EG des Europäischen Parlaments und des Rates vom 23.05. 2007 zur Einrichtung eines Aktionsprogramms für das Zollwesen in der Gemeinschaft (Zoll 2013), ABlEU Nr. L 154/25 vom 14.06. 2007; vgl. Europäische Kommission: Gesamtbericht, a. a. O., 187.

89 Rat der Europäischen Union: Mitteilung and die Presse. 2811. Tagung des Rates. Wettbewerbsfähigkeit (Binnenmarkt, Industrie und Forschung), 11155/07 vom 25.07. 2007, 16

90 2007/726/EG: Beschluss des Europäischen Parlaments und des Rates vom 23. 10. 2007 über die Inanspruchnahme des Europäischen Fonds für die Anpassung an die Globalisierung in Anwendung von Nummer 28 der Interinstitutionellen Vereinbarung vom 17. Mai 2006 zwischen dem Europäischen Parlament, dem Rat und der Kommission über die Haushaltsdisziplin und die wirtschaftliche Haushaltsführung, ABlEU Nr. L 294/21 vom 13.11. 2007; 2008/30/EG: Beschluss des Europäischen Parlaments und des Rates vom 18.12. 2007 über die Inanspruchnahme des Europäischen Fonds für die Anpassung an die Globalisierung, ABIEU Nr. L 6/9 vom 10.01. 2008. 
nehmen. ${ }^{91}$ Der Rat erzielte im November eine politische Einigung über einen gemeinsamen Standpunkt. ${ }^{92}$

\section{Gesundheit und Verbraucherschutz}

Im Oktober nahm die Kommission ein Weißbuch zur Gesundheitsförderung an. ${ }^{93}$ Hinzu kam ein Beschluss von Parlament und Rat über ein strategisches Programm für die Jahre 2008-2013. ${ }^{94}$ Ein weiteres Weißbuch hatte die Ernährung und Maßnahmen gegen Übergewicht zum Thema. ${ }^{95}$

Auf dem mit der Lebensmittelsicherheit in engem Zusammenhang stehenden Gebiet des Tierschutzes wurde eine Richtlinie zum Schutz von Masthühnern verabschiedet, die insbesondere detaillierte Regelungen zur Ausstattung der Ställe enthält. ${ }^{96}$ Darüber hinaus erschwert eine neue Verordnung die Haltung nicht heimischer Arten in Aquakulturen, um die Lebensräume in den Gewässern besser zu schützen. ${ }^{97}$

\section{Wirtschaftlicher und sozialer Zusammenhalt}

Mit Inkrafttreten der neuen Finanziellen Vorausschau für die Jahre 2007 bis 2013 setzten auch die neuen kohäsionspolitischen Programme ein, die für diesen Zeitraum ein Gesamtvolumen von 347,4 Mrd. € umfassen. Hierzu legten die Mitgliedstaaten strategische Rahmenpläne und auf deren Grundlage operationelle Programme vor. Von letzteren genehmigte die Kommission bis zum Ablauf

91 Europäisches Parlament: Legislative Entschließung des Europäischen Parlaments zu dem Vorschlag für eine Verordnung des Europäischen Parlaments und des Rates zur Einrichtung des Europäischen Technologieinstituts, P6_TA-PROV(2007)0409 vom 26.09. 2007.

92 Rat der Europäischen Union: Mitteilung an die Presse. 2832. Tagung des Rates. Wettbewerbsfähigkeit (Binnenmarkt, Industrie und Forschung), C/07/259 vom 22.11. 2007.

93 Europäische Kommission: Weißbuch. Gemeinsam für die Gesundheit: Ein strategischer Ansatz der EU für 2008-2013, KOM (2007) 630 endg. vom 23.10. 2007.

94 Beschluss Nr. 1350/2007/EG des Europäischen Parlaments und des Rates vom 23.10. 2007 über ein zweites Aktionsprogramm der Gemeinschaft im Bereich der Gesundheit (2008-2013), ABlEU Nr. L 301/3 vom 20.11. 2007.

95 Europäische Kommission: Weißbuch. Ernährung, Übergewicht, Adipositas: Eine Strategie für Europa, KOM (2007) 279 endg. vom 30.05. 2007.

96 Richtlinie 2007/43/EG des Rates vom 28.06. 2007 mit Mindestvorschriften zum Schutz von Masthühnern, ABIEU Nr. L 182/19 vom 12.07. 2007.

97 Verordnung (EG) Nr. 708/2007 des Rates vom 11.06. 2007 über die Verwendung nicht heimischer und gebietsfremder Arten in der Aquakultur, ABIEU Nr. L 168/1 vom 28.06. 2007. 
des Berichtsjahrs insgesamt 302, die aus dem Europäischen Fonds für Regionale Entwicklung und dem Kohäsionsfonds finanziert werden. ${ }^{98}$

\section{Forschung und technologische Entwicklung}

Im Rahmen des siebten Forschungsrahmenprogramms wurden die Einrichtung des Europäischen Forschungsrates (European Research Council - ERC) und seiner Organe formell beschlossen. ${ }^{99}$ Die offizielle Gründung wurde mit einer Konferenz am 27./28. Februar in Berlin begangen, erster Präsident des ERC wurde der am Imperial College in London lehrende griechische Molekularbiologe Fotis C. Kafatos, erster Generalsekretär der frühere Präsident der Deutschen Forschungsgemeinschaft Ernst-Ludwig Winnacker. ${ }^{100}$

Im Mai wurde das Scheitern der Verhandlungen über eine öffentlich-private Partnerschaft zur Finanzierung des europäischen Satellitennavigationssystems Galileo bekannt. ${ }^{101}$ Die Kommission änderte daraufhin ihren bereits in der Beratung durch Rat und Parlament befindlichen Verordnungsvorschlag und plädierte für eine ausschließlich öffentliche Finanzierung des Vorhabens. ${ }^{102}$ Die Beratung des geänderten Entwurfs durch Rat und Parlament im Mitentscheidungsverfahren stand zum Ende des Berichtsjahres noch aus.

\section{Umwelt und Energie}

Über den im Vorjahr vorgelegten Verordnungsvorschlag der Kommission zur Regulierung von Pflanzenschutzmitteln ${ }^{103}$ zeichnete sich ein politisch außergewöhnlich strittiges Rechtsetzungsverfahren ab; insbesondere versuchte die In-

98 Europäische Kommission: Umsetzung der Lissabon-Strategie für Wachstum und Beschäftigung durch die Mitgliedstaaten und Regionen im Rahmen der EU-Kohäsionspolitik, 2007-2013, KOM (2007) 798 endg. vom 11.12.2007; dies.: Gesamtbericht, a. a. O., 103.

99 2007/134/EG: Beschluss der Kommission vom 02.02. 2007 zur Einrichtung des Europäischen Forschungsrates, ABlEU Nr. L 57/14 vom 24.02. 2007.

100 Europäische Kommission: Europäischer Forschungsrat wird für europäische wissenschaftliche Exzellenz vorteilhaft sein, IP/07/223 vom 22.02. 2007; http://erc.europa.eu/.

101 FAZ vom 11.05. 2007.

102 Europäische Kommission: Geänderter Vorschlag für eine Verordnung des Europäischen Parlaments und des Rates über die weitere Durchführung der europäischen Satellitennavigationsprogramme (EGNOS und Galileo), KOM (2007) 535 endg. vom 19.09. 2007.

103 Dies.: Vorschlag für eine Verordnung des Europäischen Parlaments und des Rates über das Inverkehrbringen von Pflanzenschutzmitteln, KOM (2006) 388 endg. vom 12.07. 2006. 
dustrie, zu strenge Regelungen zu verhindern. ${ }^{104}$ Das Parlament beriet den Vorschlag im Oktober in erster Lesung und billigte ihn mit Änderungen; ${ }^{105}$ der Rat hat sich im Berichtsjahr noch nicht damit befasst.

Die existierenden Programme und Instrumente der Union im Umweltschutz wurden zu einem Finanzierungsinstrument für die Umwelt (LIFE+) zusammengefasst, dessen Mittelausstattung für den Zeitraum 2007-2013 sich auf 1,9 Mrd. $€$ beläuft. ${ }^{106}$

Auf der Grundlage einer Kommissionsmitteilung ${ }^{107}$ befasste sich der Europäische Rat auf seiner Tagung im März mit dem Klimawandel und bekräftigte das Ziel, den Temperaturanstieg auf $2{ }^{\circ} \mathrm{C}$ zu begrenzen. Er stellte in diesem Bereich weiteren Handlungsbedarf fest und einigte sich auf eine Selbstverpflichtung, die Treibhausgasemissionen bis 2020 um 20\% gegenüber 1990 zu reduzieren; zugleich forderte er zusätzliche Anstrengungen auf globaler Ebene. ${ }^{108}$ Weitere Maßnahmen enthielt ein Aktionsplan des Europäischen Rates. ${ }^{109}$

\section{Entwicklungszusammenarbeit}

Die Finanzierungsbeschlüsse der Union für Maßnahmen humanitärer Hilfe hatten 2007 ein Gesamtvolumen von 768,5 Mio. €. Davon entfiel der größte Anteil mit 422,8 Mio. $€$ auf die Region „Afrika, karibischer Raum, Pazifischer Ozean“. .110

104 FAZ vom 26.06. 2007.

105 Europäisches Parlament: Legislative Entschließung des Europäischen Parlaments zu dem Vorschlag für eine Verordnung des Europäischen Parlaments und des Rates über das Inverkehrbringen von Pflanzenschutzmitteln, P6_TA-PROV(2007)0445 vom 23.10. 2007.

106 Verordnung (EG) Nr. 614/2007 des Europäischen Parlaments und des Rates vom 23.05. 2007 über das Finanzierungsinstrument für die Umwelt (LIFE+), ABIEU Nr. L 149/1 vom 09. 06. 2007; vgl. auch Europäische Kommission: Gesamtbericht, a. a. O., 121.

107 Dies.: Begrenzung des globalen Klimawandels auf 2 Grad Celsius. Der Weg in die Zukunft bis 2020 und darüber hinaus, KOM (2007) 2 vom 10.01. 2007.

108 Europäischer Rat (Brüssel, 08./09. 03. 2007), a. a. O., Ziff. $27 \mathrm{ff}$.

109 Ebd., Anlage I.

110 Europäische Kommission: Gesamtbericht, a. a. O., 208. 


\section{Aus den Tätigkeiten der Organe und Einrichtungen}

\section{Europäisches Parlament}

In der ersten Sitzung des Jahres 2007 am 15. Januar wurden die 53 von den neuen Mitgliedstaaten Bulgarien und Rumänien entsandten Abgeordneten feierlich begrüßt. ${ }^{111}$ Diese waren von den mitgliedstaatlichen Parlamenten ernannt worden. In Bulgarien fand am 20. Mai die Direktwahl der nationalen Vertreter für den Rest der Wahlperiode statt, ${ }^{112}$ in Rumänien am 25. November, nachdem der ursprünglich für den 13. Mai angesetzte Termin aus innenpolitischen Gründen verschoben worden war. ${ }^{113}$

Unter den rumänischen Abgeordneten befanden sich mehrere Vertreter einer rechtsradikalen Partei, die zusammen mit den bereits im Parlament vertretenen Abgeordneten rechtsradikaler und rechtsextremer Parteien aus den alten Mitgliedstaaten nun die erforderliche Mitgliederzahl für eine Fraktion erfüllten. Diese bildete sich unter dem Namen „Identität, Tradition, Souveränität“ (ITS) mit 20 Mitgliedern, ${ }^{114}$ zerbrach aber bereits im November wieder an internen Auseinandersetzungen. ${ }^{115}$

Am 16. Januar wählte das Parlament turnusgemäß zur Mitte der Wahlperiode ein neues Präsidium. Zum Präsidenten wurde der bisherige Vorsitzende der EVPED-Fraktion, der deutsche Christdemokrat Hans-Gert Pöttering, gewählt; er erhielt 450 von 689 gültigen Stimmen. ${ }^{16}$ Er folgt damit auf den spanischen Sozialisten Borrell.

\section{Rat und Europäischer Rat}

Der Ratsvorsitz wurde in der ersten Hälfte des Berichtsjahrs durch Deutschland wahrgenommen, in der zweiten durch Portugal. Erstmals wurde ein gemeinsames Arbeitsprogramm dreier aufeinander folgender Präsidentschaften mit einer

111 Europäisches Parlament: Protokolle. Montag, 15.01. 2007, Straßburg, TOP 1.

112 FAZ vom 19.05. 2007.

113 FAZ vom 24.08. 2007 und vom 24.11. 2007.

114 Ebd., TOP 8; FAZ vom 17.01. 2007.

115 Europäisches Parlament: Protokolle. Mittwoch, 14.11.2007, Straßburg, TOP 4; FAZ vom 15.11. 2007.

116 Dass.: Protokolle. Dienstag, 16.01. 2007, Straßburg, TOP 3. 
Laufzeit von 18 Monaten vorgelegt, auf das sich Deutschland, Portugal und Slowenien, das den Vorsitz im ersten Halbjahr 2008 wahrnimmt, verständigt hatten. Als Schwerpunkte wurden darin die Vertragsreform, die Lissabon-Strategie, der Raum der Freiheit, der Sicherheit und des Rechts sowie die Stärkung der außenpolitischen Rolle der Union in den Bereichen Sicherheit, Entwicklung und Wirtschaftsbeziehungen benannt. ${ }^{117}$

Der Europäische Rat trat insgesamt fünfmal zusammen, darunter zweimal in informellem Rahmen. Die Sitzung im März in Brüssel befasste sich vor allem mit der Lissabon-Strategie und dem Klimaschutz. ${ }^{118}$ Noch im selben Monat, am 24. und 25. März, fand eine informelle Tagung in Berlin zur Feier des 50. Jubiläums der Römischen Verträge statt (s.o. I. 1.). Das Zusammentreffen im Juni in Brüssel stand ganz im Zeichen der Verabschiedung des Mandates für die Regierungskonferenz zur Ausarbeitung des Reformvertrages. ${ }^{119}$ Am 19. Oktober folgte - unmittelbar im Anschluss an die politische Einigung der Staats- und Regierungschefs im Rahmen der Regierungskonferenz - eine informelle Tagung in Lissabon, auf der vor allem die Rolle der Union in der Globalisierung erörtert wurde. ${ }^{120}$ Die Dezember-Sitzung in Brüssel schließlich setzte ihre Schwerpunkte im Raum der Freiheit, der Sicherheit und des Rechts, der Wirtschafts-, Sozialund Umweltpolitik sowie den Außenbeziehungen. ${ }^{121}$

\section{Europäische Kommission}

Mit Beginn des Berichtsjahres traten die beiden von den Beitrittstaaten entsandten Kommissare ihre Ämter an: Meglena Kuneva (Bulgarien) erhielt die Zuständigkeit für den Verbraucherschutz, Leonard Orban (Rumänien) wurde das Ressort Mehrsprachigkeit zugewiesen. ${ }^{122}$

117 Rat der Europäischen Union: Achtzehnmonatsprogramm des deutschen, des portugiesischen und des slowenischen Vorsitzes, 17079/06 vom 21.12. 2006.

118 Europäischer Rat (Brüssel, 08./09.03. 2007): a. a. O.

119 Europäischer Rat (Brüssel, 21./22.06. 2007): a. a. O.

120 Europäische Kommission: Gesamtbericht, a. a. O., $257 \mathrm{f}$.

121 Europäischer Rat (Brüssel, 14. 12. 2007): a. a. O.

122 Zur Ernennung vgl. Schubert, S., a. a. O., 142. 
Die Kommission trat 2007 als Kollegium 43 Mal zusammen. $\mathrm{Zu}$ den von ihr beschlossenen Dokumenten zählten 462 Vorschläge für Rechtsakte, 358 Mitteilungen und Berichte, elf Grünbücher und vier Weißbücher. ${ }^{123}$

\section{Europäischer Gerichtshof und Gericht erster Instanz}

Aus den Beitrittstaaten wurden Alexander Arabadjiev (Bulgarien) und Camelia Toader (Rumänien) am 12. Januar zu Richtern am Gerichtshof (EuGH) ernannt. ${ }^{124}$ Am Gericht erster Instanz (EuG) erfolgten am selben Tag die Ernennungen von Teodor Tchipev (Bulgarien) und Valeriu M. Ciuca (Rumänien). Am 17. September wurden als weitere EuG-Richter Alfred Dittrich (Deutschland), Sten Frimodt Nielsen (Dänemark), Santiago Soldevila Fragoso (Spanien) und Laurent Truchot (Frankreich) ernannt, die an die Stelle von Rafael GarcíaValdecasas y Fernández (Spanien), Hubert Legal (Frankreich), Jörg Pirrung (Deutschland) und Bo Vesterdorf (Dänemark, seit 1998 Gerichtspräsident) traten. Zum Nachfolger des Gerichtspräsidenten wurde der luxemburgische Richter Marc Jaeger gewählt. ${ }^{125}$

Unter den Entscheidungen erfuhr in Deutschland das Urteil zum sog. VW-Gesetz besondere Aufmerksamkeit, nach dem wesentliche Bestimmungen dieses Gesetzes nicht mit Unionsrecht vereinbar sind. ${ }^{126}$ Hinzu trat ein Entscheidung des EuG über eine Klage des Softwarekonzerns Microsoft gegen eine durch die Kommission verhängte Geldbuße wegen Missbrauchs einer marktbeherrschenden Stellung. Die Klage wurde im Wesentlichen abgewiesen. ${ }^{127}$

\section{Rechnungshof}

Der Rechnungshof legte im November seinen jährlichen Bericht zum vorangegangenen Haushaltsjahr vor. Wie schon in den Vorjahren bescheinigte er zwar die Zuverlässigkeit der Rechnungsführung, bemängelte aber, dass in weiten Bereichen die Zahlungen in erheblichem Ausmaß mit Fehlern behaftet seien, so

123 Europäische Kommission: Gesamtbericht, a. a. O., 259.

$124 \mathrm{http}: / /$ curia.europa.eu/de/instit/presentationfr/index.htm.

$125 \mathrm{http}: / /$ curia.europa.eu/common/Mandats_TPI.pdf.

126 EuGH, Urteil vom 23.10. 2007, Rs. C-112/05 (Kommission/Deutschland), noch nicht in amtlicher Sammlung veröffentlicht.

127 EuG, Urteil vom 17.09. 2007, Rs. T-201/04 (Microsoft/Kommission), noch nicht in amtlicher Sammlung veröffentlicht. 
dass er die Recht- und Ordnungsmäßigkeit der Ausgaben nicht bestätigen könne. $^{128}$

\section{Agenturen}

Der Rat beschloss am 15. Februar eine Verordnung zur Errichtung einer Agentur der Europäischen Union für Grundrechte (FRA) mit Sitz in Wien. ${ }^{129}$ Ihre wesentlichen Aufgaben sind die Forschung zum Grundrechtschutz und der Dialog mit der Zivilgesellschaft, nicht jedoch die Prüfung individueller Beschwerden.

\section{Haushalt}

Der Haushaltsplan für 2008 wurde im Laufe des Berichtsjahres erarbeitet und am 18. Dezember vom Parlament endgültig festgestellt. ${ }^{130}$ Er hat ein Gesamtvolumen von 129,1 Mrd. $€$ an Verpflichtungsermächtigungen (1,03\% des BNE der Union) und 120,3 Mrd. $€$ an Zahlungsermächtigungen (0,96\% des BNE). ${ }^{131}$ Der durch die Finanzielle Vorausschau 2007-2013 gegebene Spielraum wird damit erneut nicht ausgeschöpft.

\section{Gemeinsame Außen- und Sicherheitspolitik}

Für das Amt des EU-Sonderbeauftragten für Bosnien und Herzegowina, der zugleich Hoher Repräsentant der Internationalen Gemeinschaft in dem Land ist, würde im Juli der slowakische Diplomat Miroslav Lajčák ernannt, ${ }^{132}$ der damit dem Deutschen Christian Schwarz-Schilling nachfolgt. Der westliche Balkan blieb auch 2007 ein Schwerpunkt der Gemeinsamen Außen- und Sicherheitspolitik (GASP); daneben waren vor allem in Afrika verstärkte Aktivitäten zu verzeichnen. Besonders hervorzuheben ist die militärische Operation im Tschad und

128 Rechnungshof: Jahresbericht über die Ausführung des Haushaltsplans zum Haushaltsjahr 2006 zusammen mit den Antworten der Organe, ABIEU Nr. C 273/1 vom 15.11. 2007.

129 Verordnung (EG) Nr. 168/2007 des Rates vom 15.02. 2007 zur Errichtung einer Agentur der Europäischen Union für Grundrechte, ABlEU Nr. L 53/1 vom 22.02. 2007.

130 Europäisches Parlament: Protokolle. Dienstag, 18. 12. 2007, Brüssel, TOP 4.

$131 \mathrm{http}: / /$ ec.europa.eu/budget/budget_detail/current_year_de.htm.

132 Beschluss 2007/427/GASP des Rates vom 18.06. 2007 zur Ernennung des Sonderbeauftragten der Europäischen Union in Bosnien und Herzegowina, ABIEU Nr. L 159/63 vom 20. 06. 2007. 
der Zentralafrikanischen Republik. ${ }^{133}$ Nachdem im Vorjahr die militärische Operation im Kongo zur Überwachung der Wahlen erfolgreich durchgeführt werden konnte, ${ }^{134}$ wurden nun eine Polizeimission und eine Beratungsmission zur Reform des Sicherheitssektors in das Land entsandt. ${ }^{135}$

Insgesamt haben die Aktivitäten im Rahmen der GASP inzwischen eine beachtliche Breite und Tiefe angenommen. ${ }^{136}$ Dass daraus noch keine kohärente Außenpolitik folgt, verdeutlichten die Überlegungen im Hinblick auf die für Anfang 2008 erwartete Unabhängigkeitserklärung des Kosovo. Die Positionen der Mitgliedstaaten zur Anerkennung der Unabhängigkeit gingen weit auseinander und ließen eine Spaltung der Union in dieser wichtigen Frage befürchten. ${ }^{137}$

\section{Polizeiliche und justizielle Zusammenarbeit in Strafsachen}

Im Juli legte die Kommission einen Bericht zur Umsetzung des Europäischen Haftbefehls vor. Demnach hätten sich zwar zunächst erhebliche Verzögerungen und Schwierigkeiten ergeben, inzwischen werde das Instrument jedoch in allen Mitgliedstaaten angewendet, seine positiven Auswirkungen zeigten sich täglich, zugleich sei der Schutz der Grundrechte gewährleistet. ${ }^{138}$

133 Gemeinsame Aktion 2007/677/GASP des Rates vom 15.10. 2007 über die militärische Operation der Europäischen Union in der Republik Tschad und der Zentralafrikanischen Republik, ABlEU Nr. L 279/ 21 vom 23. 10. 2007.

134 Formelle Beendigung durch Gemeinsame Aktion 2007/147/GASP des Rates vom 27.02. 2007 zur Aufhebung der Gemeinsamen Aktion 2006/319/GASP über die militärische Operation der Europäischen Union zur Unterstützung der Mission der Organisation der Vereinten Nationen in der Demokratischen Republik Kongo (MONUC) während der Wahlen, ABIEU Nr. L 64/44 vom 02.03. 2007.

135 Gemeinsame Aktion 2007/405/GASP des Rates vom 12.06. 2007 betreffend die Polizeimission der Europäischen Union im Rahmen der Reform des Sicherheitssektors und seine Schnittstelle zur Justiz in der Demokratischen Republik Kongo (EUPOL RD Congo), ABlEU Nr. L 151/46 vom 13.06. 2007; Gemeinsame Aktion 2007/406/GASP des Rates vom 12.06. 2007 betreffend die Beratungs- und Unterstützungsmission der Europäischen Union im Zusammenhang mit der Reform des Sicherheitssektors in der Demokratischen Republik Kongo (EUSEC RD Congo), ABIEU Nr. L 151/52 vom 13.06. 2007.

136 Für eine Auflistung der im Berichtsjahr angenommenen Beschlüsse, Gemeinsamen Aktionen und Gemeinsamen Standpunkte vgl. Europäische Kommission: Gesamtbericht, a. a. O., $224 \mathrm{ff}$.

137 FAZ vom 17. 12. 2007.

138 Europäische Kommission: Bericht der Kommission über die seit 2005 erfolgte Umsetzung des Rahmenbeschlusses des Rates vom 13. Juni 2002 über den Europäischen Haftbefehl und die Übergabeverfahren zwischen den Mitgliedstaaten, KOM (2007) 407 endg. vom 11.07. 2007. 
Der Rat erließ im Juni einen Beschluss zur Regelung des Zugriffs auf personenbezogene Daten durch Europol. ${ }^{139}$ Zudem wurde einem erneuerten Abkommen mit den Vereinigten Staaten zur Übermittlung von Fluggastdaten zugestimmt, nachdem das im Vorjahr geschlossene vorläufige Abkommen zum 31. Juli auslief. Das neue Abkommen hat eine Laufzeit von sieben Jahren; es ist noch nicht formell in Kraft getreten, wird aber seit der Unterzeichnung am 16./19. Oktober vorläufig angewendet. ${ }^{140}$

\section{Fazit}

War das Vorjahr durch mehrere auch öffentlich intensiv diskutierte Entscheidungen im sekundärrechtlichen Bereich gekennzeichnet, schien die gemeinschaftliche Rechtsetzung 2007 wieder zu gewohnten Routinen zurückzukehren. Weite Aufmerksamkeit erfuhren dagegen die Ausarbeitung und Unterzeichnung des Vertrags von Lissabon, der an die Stelle des gescheiterten Verfassungsvertrages trat. Inhaltlich handelt es sich dabei im Wesentlichen um den VVE, der lediglich um symbolische Elemente bereinigt wurde; von daher erscheint eine rein parlamentarische Ratifizierung zumindest in Frankreich und den Niederlanden normativ problematisch. Gleichwohl dürfte der Vertrag einen Ausweg aus der seit 2005 andauernden „Verfassungskrise“ bieten. Voraussetzung dafür ist freilich, dass er in allen Mitgliedstaaten ratifiziert wird. Ob dies ohne größere Probleme vonstatten geht, wird sich im Jahr 2008 erweisen.

Simon Schubert

139 Beschluss der im Rat vereinigten Vertragsparteien vom 12.06. 2007 zur Annahme von Durchführungsbestimmungen zu Artikel 6a des Übereinkommens über die Errichtung eines Europäischen Polizeiamts (Europol-Abkommen) (2007/413/JI), ABIEU Nr. L 155/78 vom 15.06. 2007.

140 Beschluss 2007/551/GASP/JI des Rates vom 23.07. 2007 über die Unterzeichnung - im Namen der Europäischen Union - eines Abkommens zwischen der Europäischen Union und den Vereinigten Staaten von Amerika über die Verarbeitung von Fluggastdatensätzen (Passenger Name Records - PNR) und deren Übermittlung durch die Fluggesellschaften an das United States Department of Homeland Security (DHS) (PNR-Abkommen von 2007), ABIEU Nr. L 551/16 vom 04.08. 2007; Agreement Database des Rates der Europäischen Union. 